\title{
Precipitation mediates the temporal dynamics of net primary productivity and precipitation use efficiency in China's northern and southern forests
}

\author{
Jian Sun ${ }^{1,2} \cdot$ Tiancai Zhou ${ }^{1,3,4} \cdot$ Wenpeng $\mathrm{Du}^{1,3} \cdot$ Yanqiang Wei $^{5}$ \\ Received: 11 June 2018 / Accepted: 16 August 2019 / Published online: 3 September 2019 \\ (C) INRA and Springer-Verlag France SAS, part of Springer Nature 2019
}

\begin{abstract}
- Key message Precipitation mediates the dynamic of net primary productivity and precipitation use efficiency across the North-South Transect forests of China, which may result from an increase of productivity in warm temperate deciduous broad-leaved forests or a decrease of precipitation use efficiency in temperate coniferous broad-leaved mixed forests.

- Context Precipitation use efficiency (PUE), the ratio of net primary productivity (NPP) to annual precipitation, is one of the key factors that can clarify the response of forest ecosystem carbon and water cycles to ongoing climate change.

- Aims To investigate large-scale patterns of NPP and PUE, and to determine how NPP and PUE would respond to climate and soil variables across the North-South Transect forests (TNSTF) of China.

- Methods We revealed the spatial pattern dynamics of NPP and PUE in the TNSTF from 2000 to 2010 employing MOD17 NPP data and further explored the responses of NPP and PUE to environment factors across the TNSTF. Additionally, the temporal dynamics of NPP and PUE in different forest types and their dependencies on climate variation were investigated.

- Results The results indicated that NPP increased from 2000 to 2010 in most regions across the TNSTF. The spatial distribution pattern of NPP was mainly correlated with climate factors in the TNSTF rather than soil properties. Spatially, an increased trend of PUE (2000-2010) was found in the south and decreased PUE was revealed in the north of the TNSTF. In addition, the spatial distribution of PUE in the TNSTF was associated with both climate and soil factors. For different forests, only the NPP in warm temperate deciduous broad-leaved forests significantly increased $\left(2000-2010, R^{2}=0.33, P<0.05\right)$ due to the increase in precipitation $\left(R^{2}=0.82, P<0.0005\right)$. Moreover, only the PUE in temperate coniferous broad-leaved mixed forests presented a
\end{abstract}

Handling Editor: Barry Alan Gardiner

Contribution of the co-authors

J.S. and T.C.Z. designed the analysis; J.S., T.C.Z., W.P.D., and Y.Q.W. were involved in drafting or revising the manuscript. All authors read and approved the final manuscript.

Tiancai Zhou

zhoutc.18b@igsnrr.ac.cn

Jian Sun

sunjian@igsnrr.ac.cn

Wenpeng $\mathrm{Du}$

duwenpeng7028@163.com

Yanqiang Wei

weiyq@1zb.ac.cn

1 Synthesis Research Centre of Chinese Ecosystem Research Network, Key Laboratory of Ecosystem Network Observation and Modelling, Institute of Geographic Sciences and Natural Resources Research, Chinese Academy of Sciences, Beijing 100101, China
2 State Key Laboratory of Urban and Regional Ecology, Research Center for Eco-environmental Sciences, Chinese Academy of Sciences, Beijing 100085, China

3 College of Resources and Environment, University of Chinese Academy of Sciences, Beijing 100190, China

4 Lhasa Plateau Ecosystem Research Station, Key Laboratory of Ecosystem Network Observation and Modeling, Institute of Geographic Sciences and Natural Resources Research, Chinese Academy of Sciences, Beijing 100101, China

Key Laboratory of Remote Sensing of Gansu Province, Northwest Institute of Eco-Environment and Resources, Chinese Academy of Sciences, Lanzhou 730000, People's Republic of China 
significantly decreasing trend (2000-2010, $\left.R^{2}=0.38, P<0.05\right)$, which was significantly negatively correlated with precipitation $\left(R^{2}=0.80, P<0.0005\right)$.

- Conclusion Our findings demonstrated that climate governed the spatial distribution of NPP; in addition to the climate, soil properties also played an important role in shaping the spatial distribution of PUE. Our findings highlight that the dynamics of precipitation rather than those of temperature mediated the variations in NPP and PUE in forests across the TNSTF.

Keywords Precipitation use efficiency $\cdot$ Net primary production $\cdot$ Climate $\cdot$ Forest ecosystem $\cdot$ The north-south transect $\cdot$ China

\section{Introduction}

Ecosystem structure and function are significantly affected by global climate change (Kerr and Packer 1998; Williams 2000). During the past two decades, the annual mean air temperature (AMT) in China increased at a rate of $0.6{ }^{\circ} \mathrm{C}$ decade $^{-1}$ (Piao et al. 2011). Associated with the warming, significant changes in carbon cycle were also observed (Huang et al. 2017). Forest ecosystems, as principal components of terrestrial ecosystems, play crucial roles in regulating and shaping the global carbon balance and sequestering greenhouse gases (Fang et al. 2014; Houghton 2007; Pan et al. 2009). A persistent change in climate could generate unprecedented variations in forest growth, especially for forest productivity (Morin et al. 2018). The net primary productivity (NPP) of forests is the amount of carbon uptake by subtracting the autotrophic respiration from the gross primary productivity of forests (Lieth and Whittaker 1975), which acts as a pivotal regulator in the global carbon cycle because it reflects the capacity of forest atmospheric $\mathrm{CO}_{2}$ uptake and carbon sequestration (Cramer et al. 2001; Steffen et al. 1998), and it is closely related to precipitation use efficiency (PUE). PUE is defined as the ratio of biomass to rainfall and reflects the ability of vegetation to convert nutrients into biomass through water utilization (Kato et al. 2004; Lehouerou 1984; Yin et al. 2011). In other words, PUE links the carbon cycle with the hydrologic cycle in forest ecosystems (Ling et al. 2007), and it is an effective index for evaluating the responses of NPP to precipitation and temperature (Le et al. 1988; Sala et al. 1988). Thus, NPP and PUE are critical components for evaluating the function of forest ecosystems and for analyzing the effects of climate change on the carbon cycle (Fang et al. 2014).

A slight change in NPP will greatly influence $\mathrm{CO}_{2}$ concentration in the atmosphere, and NPP therefore is essential to quantify C budgets for grasslands (Wang et al. 2007) and forests (Wang et al. 2011). Indeed, numerous studies have estimated NPP with models (Monteith 1972), identified the control mechanisms on forest NPP with climate and other environmental factors (Morales et al. 2010), and addressed how forest NPP responds to climate in China (Fang et al. 2003). Generally, the responses of forests to climate change have different sensitivities and characteristics in China, with heterogeneous temporal and spatial patterns (Wang et al. 2011; Zhu et al. 2007). In addition, PUE could be another critical indicator for quantifying the responses of forest ecosystems to an altered climate (Yang et al. 2010).
Previous reports found that PUE decreased with increasing annual precipitation in grasslands on the Mongolian plateau (Bai et al. 2008), increased under more severe dry conditions (Maseyk et al. 2011) or under relatively greater reductions in stomatal conductance (Nock et al. 2011), and $4.23 \%$ and $1.29 \%$ of the total area of the West Songliao Plain experienced a significant increase and decrease in PUE relative to the average (Huang and Xu 2016), respectively. Numerous factors influence PUE, including temperature ( $\mathrm{Li}$ et al. 2013; Xie et al. 2016), precipitation (Limousin et al. 2015), leaf area index (Xie et al. 2016), air pollution (Kwak et al. 2016), gross primary production and evapotranspiration (Brümmer et al. 2012), soil water content, solar radiation, and atmospheric saturation deficit (Xie et al. 2016). Specifically, PUE increases with increased atmospheric $\mathrm{CO}_{2}$ concentrations in temperate deciduous forests (Jennings et al. 2016; Maseyk et al. 2011). In addition, higher PUE was observed in $\mathrm{N}$ fertilization plots in grasslands (Bai et al. 2008), and $\mathrm{N}$ fertilization as well as $\mathrm{CO}_{2}$ had synergistic effects on PUE in a temperate deciduous forest (Jennings et al. 2016). Moreover, PUE presented a declining trend with increasing annual mean precipitation (AMP) in a karst ecosystem (Li et al. 2015) and in grasslands (Bai et al. 2008). For the north-south transect forests (TNSTF) of China, studies found that PUE was significantly positively correlated with stomatal area fraction at community level across forests (Xian et al. 2017) and had significant negative relationships with temperature and precipitation (Yu et al. 2008). Nevertheless, considering that soil properties are key parameters for evaluating the response of PUE to climate change in forests, there is scant evidence from large-scale areas, such as the TNSTF of China.

The question of which factors (climate or soil factors) dominate the distribution of NPP/PUE, whether there are different dynamic patterns of NPP/PUE responses to climate change in the TNSTF remain unclear. To confirm the indicators of the controls on temporal-spatial variations of forests' NPP/PUE, explicit information on the impact of climate or other environmental conditions on NPP/PUE is critical. Therefore, we selected the 15th belt transect of the International Geosphere-Biosphere Program (IGBP) TNSTF in China to disentangle (1) the relationships between NPP/PUE and environment factors (AMT, AMP, 
soil organic matter (SOM), soil total nitrogen (STN), soil total phosphorus (STP), soil total kalium (STK), soil available nitrogen (SAN), soil available phosphorus (SAP), and soil available kalium (SAK)) at a regional scale; and (2) which climate factors dominate the significant variations of NPP/PUE in different forests.

\section{Materials and methods}

\subsection{Study area}

The study area covers the northern and southern forests in China within the 15th standard strip of the IGBP, which is a good platform for studying forests covering a broad area and rich vegetation types. The study area encompassed $7.4 \times$ $10^{5} \mathrm{~km}^{2}$ of forests in northern and southern China, which includes $35.58 \%$ of China's forest ecosystem and $7.71 \%$ of China's land area, ranging from $18^{\circ} 9^{\prime} 34^{\prime \prime} \mathrm{N}$ to $50^{\circ} 31^{\prime} 40^{\prime \prime} \mathrm{N}$ and $107^{\circ} 49^{\prime} 11^{\prime \prime} \mathrm{E}$ to $127^{\circ} 59^{\prime} 47^{\prime \prime} \mathrm{E}$, and including a total of 26 administrative provinces. The area covers the tropical rain forests/monsoon forests (TRF), subtropical evergreen broadleaved forests (SEBF), warm temperate deciduous broadleaved forests (WTDBF), temperate coniferous broad-leaved mixed forests (TCBMF), and cool deciduous coniferous forests (CDCF) from the South to the North (Fig. 1). The predominant species, soil type, biomass, and distribution area of each forest type are shown in Table 1 (Fang 1992; Li et al. 2004).

\subsection{Data preparation}

The NPP data from 2000 to 2010 were downloaded from the NASA Moderate Resolution Imaging Spectroradiometer (MODIS) MOD17 NPP products (http://modis.gsfc.nasa. gov/data/dataprod/mod17.php). The NPP product is the continuous and satellite-driven dataset for monitoring global annual vegetation productivity with a $1 \mathrm{~km} \times 1 \mathrm{~km}$ resolution.

The data on soil $\mathrm{C}$ and soil $\mathrm{N}$ density (with a soil depth of $100 \mathrm{~cm}$ ) are downloaded from the Oak Ridge National Laboratory Distributed Active Archive Center (ORNL DAAC) (https://daac.ornl.gov/). The ORNL DAAC is one of the NASA Earth Observing System Data and Information System (EOSDIS) data centers managed by the Earth Science Data and Information System (ESDIS) Project, which is responsible for providing scientific and other users' access to data from NASA's Earth Science Missions.

The temperature and precipitation data were collected from the 740 China Meteorological Administration climate stations from 2000 to 2010 (http://cdc.cma.gov.cn), and the meteorological data were processed to obtain annual mean temperature (AMT) and AMP. The spatial interpolation of AMT and AMP were processed in ArcGIS 10.2 (ESRI, Inc., Redlands, CA, USA) using the kriging interpolation method.
Fig. 1 The study area encompassed China's northern and southern forests. The forests include tropical rain forests monsoon forests (TRF), subtropical evergreen broadleaved forests (SEBF), warm temperate deciduous broadleaved forests (WTDBF), temperate coniferous broad-leaved mixed forests (TCBMF), and cool deciduous coniferous forests (CDCF)

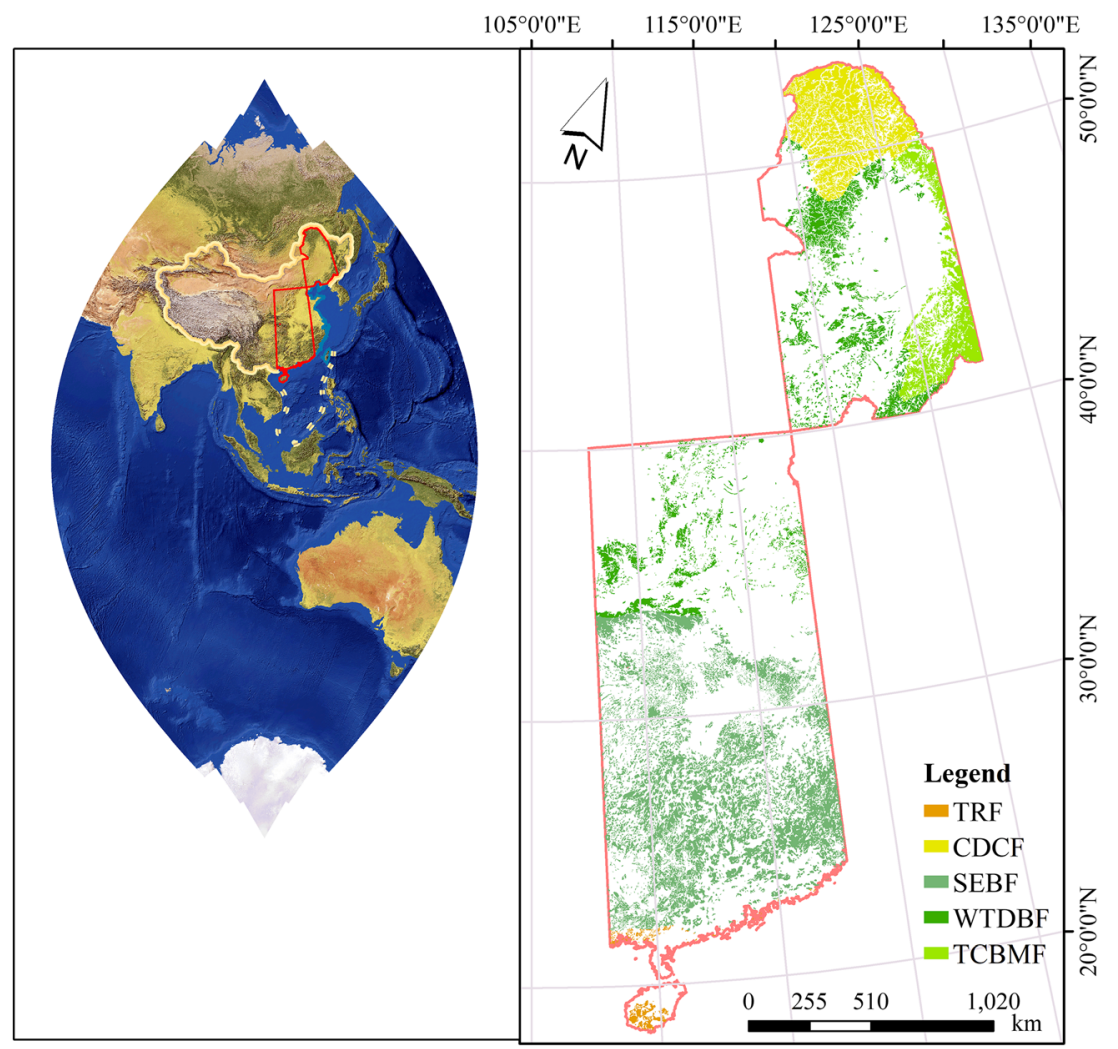


Table 1 The predominant species, soil type, and distribution of different forest types in China's northern and southern forests

\begin{tabular}{|c|c|c|c|c|}
\hline Forest types & $\begin{array}{l}\text { Acronyms } \\
\text { of forest } \\
\text { types }\end{array}$ & Predominant species & Soil type & Distribution area \\
\hline $\begin{array}{l}\text { Cool deciduous } \\
\text { coniferous forests }\end{array}$ & $\mathrm{CDCF}$ & $\begin{array}{l}\text { Larix gmelinii, Populus davidiana, } \\
\text { and Betula }\end{array}$ & $\begin{array}{l}\text { Dark brown forest } \\
\text { soil }\end{array}$ & Inner Mongolia and Heilongjiang \\
\hline $\begin{array}{l}\text { Temperate coniferous } \\
\text { broad-leaved mixed } \\
\text { forests }\end{array}$ & TCBF & $\begin{array}{l}\text { Pinus koraiensis, Abies fabri, Tilia } \\
\text { amurensis, and Populus } \\
\text { davidiana }\end{array}$ & $\begin{array}{l}\text { Dark brown forest } \\
\text { soil }\end{array}$ & Heilongiiang, Jilin, and Liaoning \\
\hline $\begin{array}{l}\text { Warm temperate } \\
\text { deciduous } \\
\text { broad-leaved forests }\end{array}$ & WTDBF & $\begin{array}{l}\text { Fagus, Quercus dentate, and } \\
\text { Quercus acutissima }\end{array}$ & Cinnamon soil & $\begin{array}{l}\text { Inner Mongolia, Liaoning, Shandong, Shanxi, } \\
\text { Shanxi, and Henan }\end{array}$ \\
\hline $\begin{array}{l}\text { Subtropical evergreen } \\
\text { broad-leaved forests }\end{array}$ & SEBF & $\begin{array}{l}\text { Fagaceae, Pinus massoniana, and } \\
\text { Phoebe zhennan }\end{array}$ & $\begin{array}{l}\text { Lateritic red soil, } \\
\text { yellow soil and } \\
\text { brown soil }\end{array}$ & $\begin{array}{l}\text { Shanxi, Henan, Anhui, Hubei, Hunan, Jiangxi, } \\
\text { Fujian, Chongqing, Guizhou, Guangxi, and } \\
\text { Guangdong }\end{array}$ \\
\hline $\begin{array}{l}\text { Tropical rain forests and } \\
\text { monsoon forests }\end{array}$ & TRF & $\begin{array}{l}\text { Annonaceae, Combretaceae, } \\
\text { Sterculiaceae, and Moraceae }\end{array}$ & Latosol & Hainan \\
\hline
\end{tabular}

\subsection{Data analyses}

The PUE is defined as the ratio of NPP to precipitation (Lehouerou 1984) to reflect the ability of vegetation to convert nutrients into biomass through water use (Kato et al. 2004; Lehouerou 1984; Yin et al. 2011). Thus, the PUE can be calculated from NPP and AMP (Eq. 1) (Sun and Du 2017).

$\mathrm{PUE}=\frac{\mathrm{NPP}}{\mathrm{AMP}}$

To analyze the temporal and spatial dynamics of NPP and PUE and to reveal the relationships between NPP, PUE, and environmental factors, we applied the least squares method in this analysis. The spatial change rates of NPP and PUE and the spatial correlation relationships between NPP or PUE and AMT or AMP were calculated by Eq. 2 and Eq. 3 (Sun et al. 2013):

$\beta=\frac{n \sum X Y-\sum X \sum Y}{n \sum X^{2}-\left(\sum X\right)^{2}}$

$r=\frac{n \sum_{i=1}^{n} x_{i} y_{i}-\sum_{i=1}^{n} x_{i} \sum_{i=1}^{n} y_{i}}{\sqrt{n \sum_{i=1}^{n} x_{i}^{2}-\left(\sum_{i=1}^{n} x_{i}\right)^{2}}-\sqrt{n \sum_{i=1}^{n} y_{i}^{2}-\left(\sum_{i=1}^{n} y_{i}\right)^{2}}}$

where $\beta$ and $r$ are the spatial change rate and the spatial correlation coefficient, respectively, $n$ is the number of years in the study period, $X$ is the year, $Y$ is the NPP or PUE, $x_{i}$ is the AMT or AMP, and $y_{i}$ is the NPP or PUE.

The R software package "corrgram" (R Core Development Team, R Foundation for Statistical Computing, Vienna, Austria) was applied to analyze the relationships between environment factors and the distributions of NPP and PUE. The redundancy analysis (RDA) in R was applied to determine the influence of environment factors on the variations in NPP and PUE. Linear regression analysis was used in the SigmaPlot 10.0 software (Systat Software, Inc., Chicago, IL, USA) to generate the correlations between NPP or PUE and environmental factors.

\section{Results}

\subsection{Spatial distribution and dynamics of climate, NPP, and PUE in China's northern and southern forests}

The annual average of NPP during the period of 2000-2010 ranged from 0 to $2999.69 \mathrm{~g} \mathrm{C} \mathrm{m}^{-2}$ year $^{-1}$. The results indicated that the largest values of NPP were mainly distributed in areas of the provinces of Hainan, Guangdong, and Fujian that are mainly covered by TRF and SEBF (Fig. 2a). Additionally, the lowest values of NPP were found in the provinces of Inner Mongolia and Heilongjiang, where the forests were mainly comprised of CDCF, and the values of NPP were less than $587.00 \mathrm{~g} \mathrm{C} \mathrm{m}^{-2}$ year $^{-1}$ (Fig. 2a). Spatially, the average value of PUE (2000-2010) presented a pattern of large values in the north, in the provinces of Henan and Shanxi, and low values in other regions (Fig. 2b). In detail, PUEs with values exceeding $1.12 \mathrm{~g} \mathrm{C} \mathrm{m}^{-2} \mathrm{~mm}^{-1}$ were primarily found in the provinces of Inner Mongolia, Heilongjiang, Henan, Shanxi, and Hainan, while PUEs below $0.57 \mathrm{~g} \mathrm{C} \mathrm{m}^{-2} \mathrm{~mm}^{-1}$ were mainly observed in the provinces of Hubei, Hunan, and Jiangxi.

Moreover, during 2000-2010, the NPP showed an increased trend in most regions across the TNSTF (Fig. 2c). However, some regions in the middle of the study area where SEBF is distributed presented a decreasing tendency during 2000-2010. For the dynamics of PUE, increased PUEs (2000-2010) were primarily distributed in the centre-south of the study area, including the TRF, SEBF, and WTDBF 
Fig. 2 Spatial patterns and dynamics of net primary productivity (NPP) and precipitation use efficiency (PUE) across China's northern and southern forests from 2000 to 2010. Graphs a and b represent spatial distributions of average NPP and PUE, respectively, while graphs $\mathbf{c}$ and $\mathbf{d}$ represent variations in the temporal change of NPP and PUE, respectively

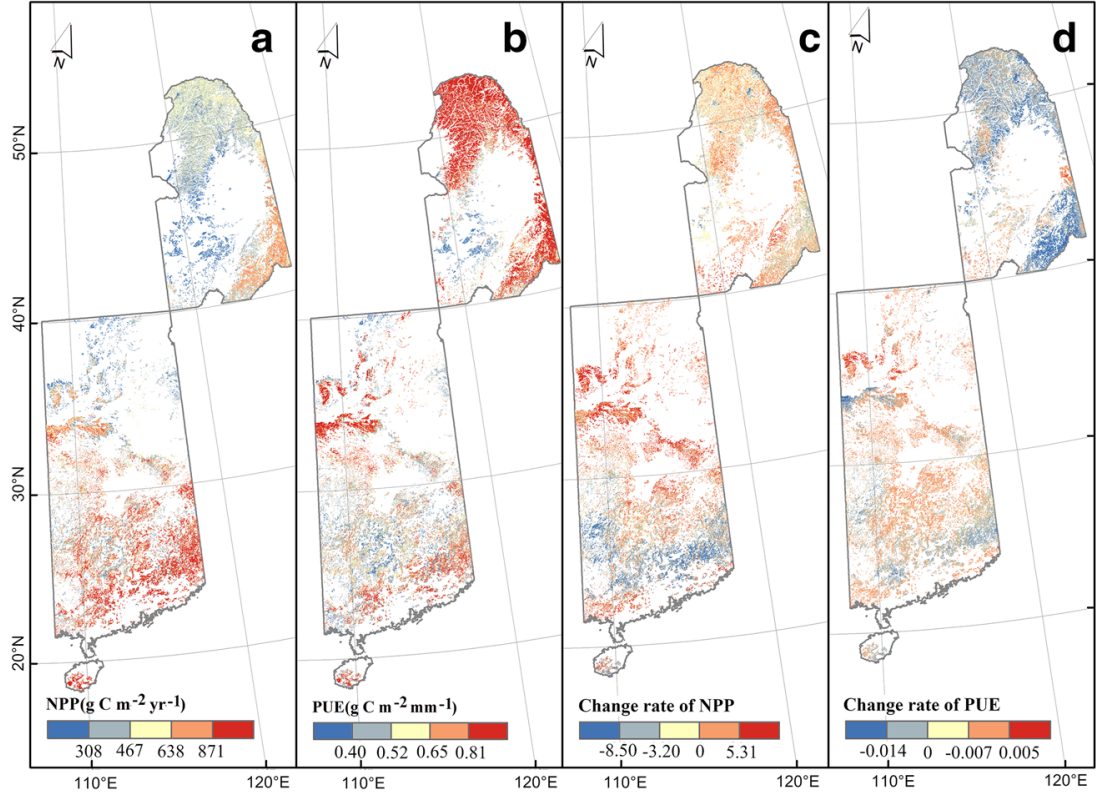

(Fig. 2d). At the same time, decreased PUEs (2000-2010) were mainly present in the TCBMF and CDCF, which are primarily distributed in Jilin, Liaoning, and the north of Inner Mongolia.

Spatially, the results demonstrated that both AMP and AMT (average value during 2000-2010) had higher values in the south and low values in the north (Fig. 3a, b). Meanwhile, the AMP showed an increased trend in the North from 2000 to 2010, where the CDCF, TCBMF, and WTDBF are distributed, and the AMP presented a decreased trend in the South from 2000 to 2010, where the SEBF and TRF (Fig. 3c) are distributed. In addition, during 2000-2010, a decreasing trend in AMT in the CDCF and TRF and a part of the WTDBF was observed, while an increasing trend in AMT in TCBMF and SEBF was revealed (Fig. 3d).

\subsection{Responses of NPP and PUE to precipitation and temperature variations across China's northern and southern forests}

An obvious positive correlation between NPP and precipitation was shown in most of the regions across the TNSTF, except in the North and in a part of the South (Fig. 4a). Conversely, a negative relationship between PUE and precipitation was revealed in most areas of the TNSTF (Fig. 4b). Additionally, there were positive correlations between NPP/ PUE and AMT in most locations throughout the study area (Fig. 4c, d). Specifically, the significance analysis showed that AMP played an important role in shaping the dynamics of PUE (Fig. 5b), and AMP also influenced the variation in NPP in the north of the TNSTF (Fig. 5a). However, the correlations between variations in NPP/PUE and AMT were not significant in most regions of the TNSTF (Fig. 5c, d).

\subsection{Relative importance of the climate factors and soil factors for the dynamics of NPP and PUE}

To further explore the responses of NPP and PUE to the environment factors, we extracted the average values of NPP, PUE, AMP, and AMT during the period of 2000-2010 as well as the soil properties at 7291 points (uniformly distributed in the TNSTF with the "fishnet" tool in ArcGis). The results indicated that there was a significant positive correlation between NPP and AMP $\left(R^{2}=0.58, P<0.05\right.$, Fig. $\left.6 \mathrm{a}\right)$, and there was a similar relationship between AMT and NPP $\left(R^{2}=0.48\right.$, $P<0.05$, Fig. 6a). Nevertheless, non-significant negative relationships between NPP and soil properties were found (Fig. 6a). Moreover, significant negative relationships were revealed between PUE and AMP $\left(R^{2}=0.46, P<0.05\right.$, Fig. 6b) and PUE and AMT $\left(R^{2}=0.53, P<0.05\right.$, Fig. $\left.6 \mathrm{~b}\right)$, while a significant positive correlation was demonstrated between PUE and soil properties (Fig. 6b). In general, the climate factors together with the soil factors explained $34.48 \%$ (Fig. 7a) and $30.47 \%$ (Fig. 7b) of the variations in NPP and PUE, respectively. Notably, compared with soil factors, the climate factors had a relatively larger influence on NPP, whereas the PUE was mediated by both the climate and soil factors (Fig. 7).

\subsection{Dominant climate factors for the significant variations in NPP and PUE in different forests}

According to the above research, the results demonstrated that, compared with soil factors, the distributions of NPP and PUE in the TNSTF were most correlated with climate factors (Fig. 6a, b). Hence, we explored the dynamics of NPP/PUE and the response of NPP/PUE to the variations in 
Fig. 3 Spatial patterns and dynamics of annual mean precipitation (AMP) and annual mean temperature (AMT) across China's northern and southern forests from 2000 to 2010. Graphs a and b represent spatial distributions of AMP and AMT, respectively, while graphs $\mathbf{c}$ and $\mathbf{d}$ represent variations in the temporal change of AMP and AMT, respectively

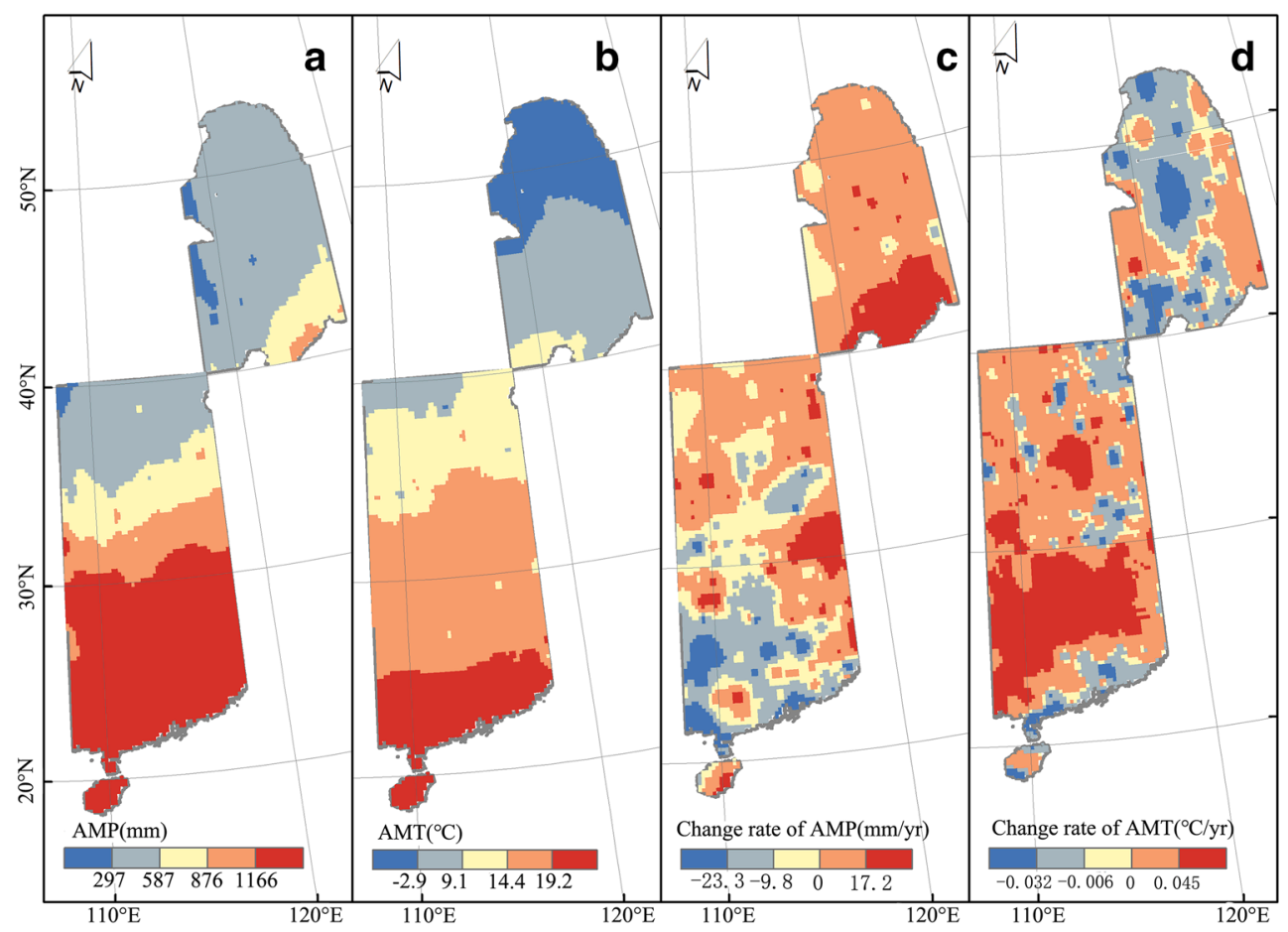

climate in different forests. The findings indicated that NPP showed a significantly increasing trend in $\operatorname{WTDBF}\left(R^{2}=0.33\right.$, $P<0.05$, Table 2) and there was a significant decrease in PUE in TCBMF $\left(R^{2}=0.38, P<0.05\right.$, Table 2$)$. Non-significant NPP/PUE dynamics were found in other forests (Table 2). Moreover, the relationships between the climate and the significant change in NPP/PUE indicated that the increase in
NPP in WTDBF was significantly positively correlated with AMP $\left(R^{2}=0.82, P<0.0005\right.$, Fig. 8 b), and the decrease in PUE in was significantly negatively associated with AMP $\left(R^{2}=0.80, P<0.0005\right.$, Fig. 8d). However, non-significant relationships were found between the variations in NPP and AMT in WTDBF (Fig. 8a), PUE, and AMT in TCBMF (Fig. 8c).
Fig. 4 Responses of net primary productivity (NPP) and precipitation use efficiency (PUE) to variations in annual mean precipitation (AMP) and annual mean temperature (AMT) across China's northern and southern forests. Graphs a and $\mathbf{b}$ represent responses of NPP and PUE to AMP, respectively. Graphs $\mathbf{c}$ and d response of NPP and PUE to AMT, respectively

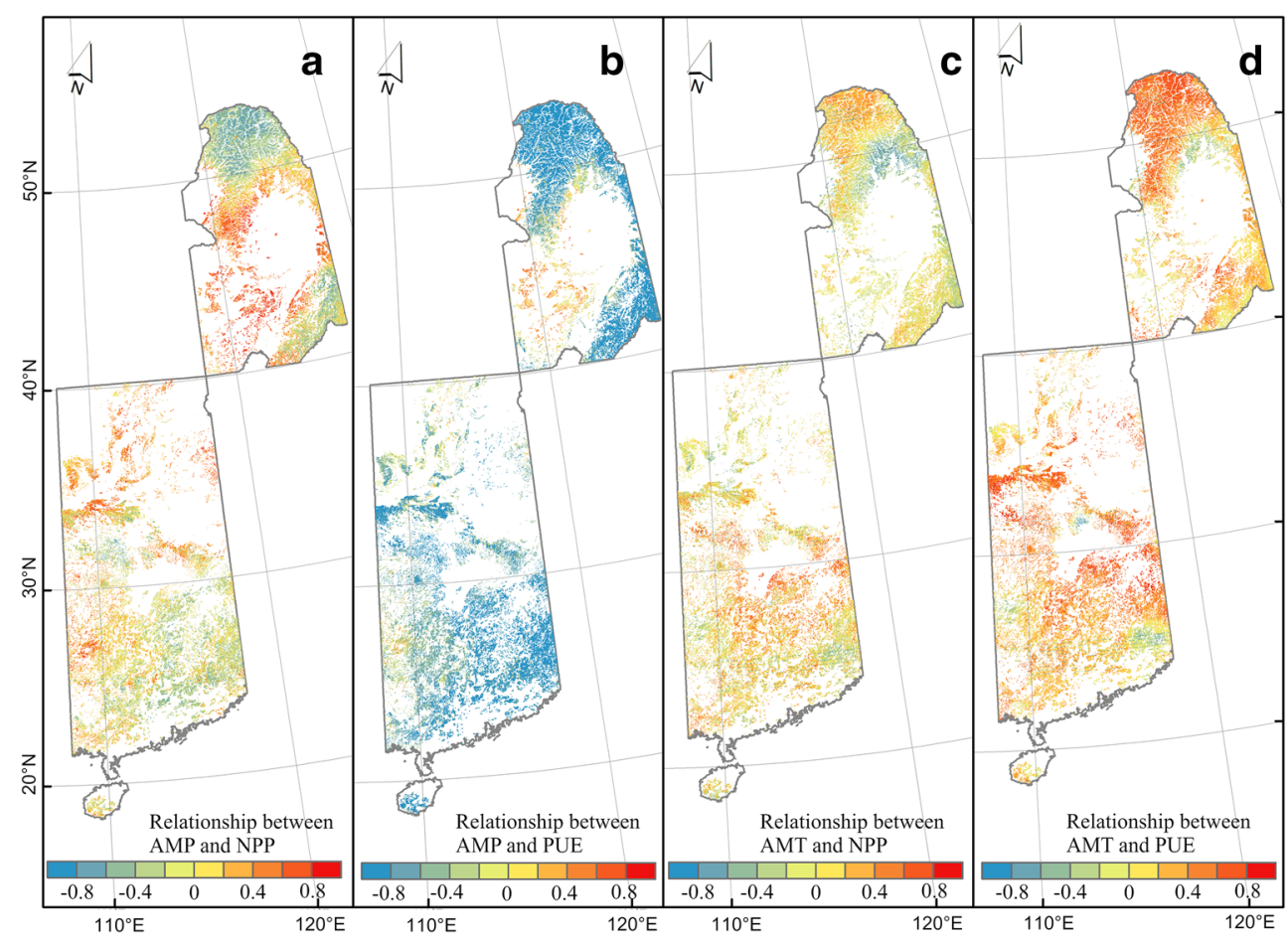


Fig. 5 Analysis of the significance in the response of net primary productivity (NPP) and precipitation use efficiency (PUE) to variations in annual mean precipitation (AMP) and annual mean temperature (AMT) across China's northern and southern forests. Graphs a and b represent the responses of NPP and PUE to AMP, respectively. Graphs $\mathbf{c}$ and d represent the responses of NPP and PUE to AMT, respectively

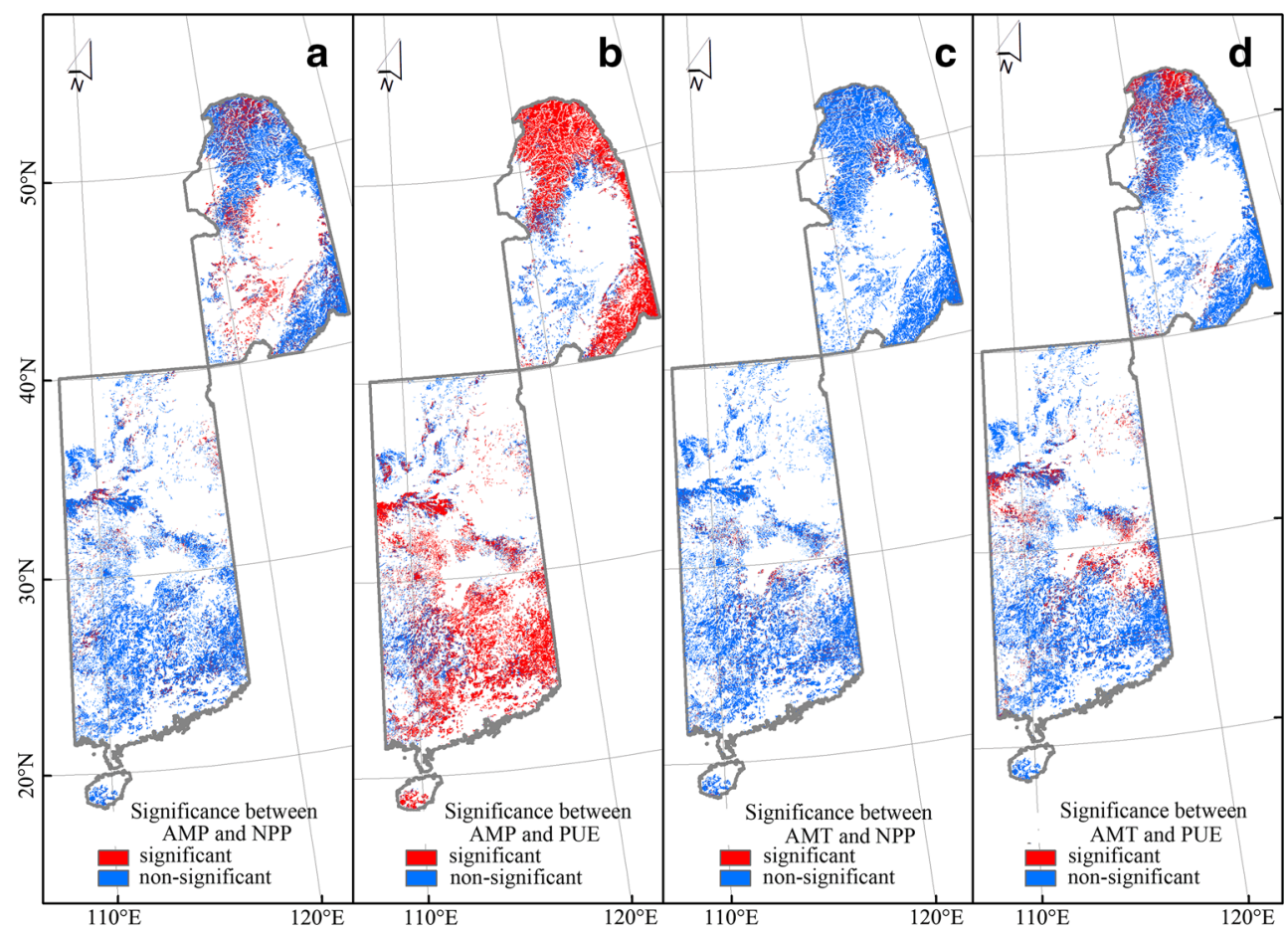

\section{Discussion}

\subsection{Spatial changes and control mechanisms of NPP in the north-south transect forests over China}

Previous studies have found that the spatial distribution of NPP tended to increase from north to south in the TNSTF of China (Li et al. 2004; Wang 2010), and our results were consistent with these prior findings (Fig. 2a). The change rate of NPP manifested that NPP increased in most areas throughout the TNSTF from 2000 to 2010 (Fig. 2c), and the spatial dynamics of NPP were significantly correlated with AMP followed by AMT (Fig. 6a). Recent studies also have suggested that the main driver for NPP variation is precipitation; temperature also plays a supporting role (Cao et al. 2003; Cleveland et al. 2011).
The increased spatial precipitation in the TNSTF (Fig. 3c, Table 2) improves the soil water supply, enhances the photosynthetic rate, and eventually increases the NPP spatially (Fig. 2c). Additionally, increased spatial temperature in the TNSTF (Fig. 3c) can extend the growth cycle of vegetation and improve NPP through metabolically enhancing photosynthesis (Ouyang et al. 2014). However, in SEBF, the climate appears to have a trend of warming-drying (Ren et al. 2011), the decreased precipitation could weaken plant photosynthesis (Fig. 3c), and the increased temperature (Fig. 3c) could enhance plant respiration (Sitch et al. 2008), correspondingly resulting in a decrease in NPP (Fig. 2c). Meanwhile, non-significant relationships between soil factors and NPP (Fig. 6a) suggest that the growth of the forests was more impacted by climate than soil nutrient availability.
Fig. 6 The relationships between net primary productivity (NPP) and environment factors (a), precipitation use efficiency (PUE) and environment factors (b). Environment factors including the annual mean precipitation (AMP), annual mean temperature (AMT), soil organic matter (SOM), soil total nitrogen (STN), soil total phosphorus (STP), soil total kalium (STK), soil available nitrogen (SAN), soil available phosphorus (SAP), and soil available kalium (SAK)
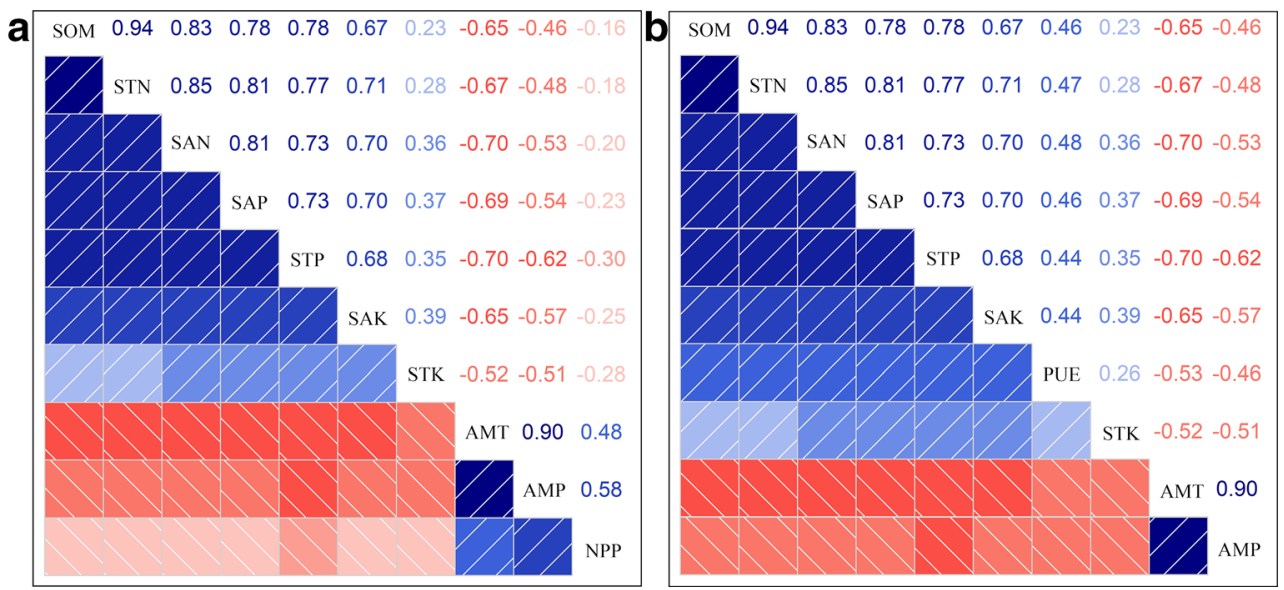


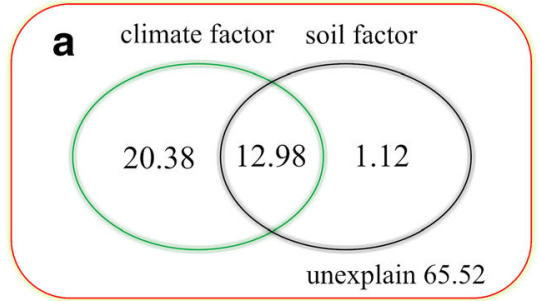

Fig. 7 Variance in net primary productivity (NPP) (a) and precipitation use efficiency (PUE) (b) across the China's northern and southern forests can be explained by climate (annual mean precipitation (AMP) and annual mean temperature (AMT)) as well as soil factors (soil organic

As for the dynamics of NPP over the TNSTF, a significant increase in NPP was found only in WTDBF, which was mainly affected by the increase (Table 2) in AMP $\left(R^{2}=0.82\right.$, $P<0.0005$, Fig. 8b). Actually, because of changes in the climate, the increase in NPP had already been found in the North temperate zone (Wang 2010). With AMP less than $500 \mathrm{~mm}$ in WTDBF (Table 2), the soil nutrition content would be increased by leaching due to the increase in precipitation because the inorganic elements in soil are mainly derived from the mineralization of soil rock (Acquaye 1963; Guo and Yost 1998). Later, for plants, the mineralization, accumulation, and absorption of soil elements could also be increased (Papanikolaou et al. 2010) when AMT and AMP increase in WTDBF (Table 2). Consequently, the accumulation of

Table 2 The variation of NPP and PUE in different forests (cool deciduous coniferous forests (CDCF), temperate coniferous broadleaved mixed forests (TCBMF), warm temperate deciduous broadleaved forests (WTDBF), subtropical evergreen broad-leaved forests (SEBF), and tropical rain forests, monsoon forests (TRF)) across the North-South Transect forests in China (2000-2010). $y$ is the indicator of NPP and PUE; $x$ is the years 2000-2010; $y_{0}$ is the intercept; and $a$ is the slope; $R^{2}$ is the linear correlation coefficient

\begin{tabular}{lllll}
\hline & Forest types & $y=\mathrm{a} x+y_{0}$ & $R^{2}$ & Mean \\
\hline NPP & CDCF & $y=-1.19 x+591.82$ & 0.006 & 585.26 \\
& TCBMF & $y=-0.43 x+810.55$ & 0.001 & 808.18 \\
& WTDBF & $y=6.49 x+399.70$ & $0.326^{*}$ & 435.41 \\
& SEBF & $y=-3.36 x+1020.20$ & 0.022 & 1001.76 \\
& TRF & $y=3.29 x+1513.30$ & 0.012 & 1531.42 \\
PUE & CDCF & $y=-0.019 x+1.49$ & 0.035 & 1.39 \\
& TCBMF & $y=-0.028 x+1.37$ & $0.384^{*}$ & 1.22 \\
& WTDBF & $y=-0.005 x+0.92$ & 0.069 & 0.89 \\
& SEBF & $y=-0.001 x+0.75$ & 0.001 & 0.74 \\
& TRF & $y=0.002 x+0.85$ & 0.001 & 0.86 \\
AMP & WTDBF & $y=10.26 x+441.04$ & 0.231 & 497.45 \\
AMT & WTDBF & $y=0.001 x+7.28$ & 0.000 & 7.27 \\
AMP & TCBMF & $y=20.00 x+580.32$ & $0.381^{*}$ & 690.29 \\
AMT & TCBMF & $y=0.008 x+4.47$ & 0.002 & 4.51 \\
\hline
\end{tabular}

* Represents significance at the level of 0.05 .

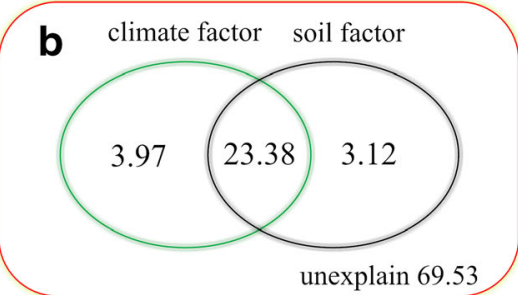

matter (SOM), soil total nitrogen (STN), soil total phosphorus (STP), soil total kalium (STK), soil available nitrogen (SAN), soil available phosphorus (SAP), and soil available kalium (SAK)) using redundancy analysis

biomass is promoted (Chiu et al. 2006; Ross et al. 1996). However, some studies have shown that AMP did not account for the variation in NPP in tropical forests (Cleveland et al. 2011) because rainfall could lead to loss of soil nutrient in the tropical zone, and other studies found that increased temperature and decreased precipitation explained the increasing trend of forest NPP in North-eastern China (Mao et al. 2014). The reason for the different responses of NPP to climate could be that the responses of forests to climate change have different sensitivities and characteristics (Gao and Zhang 1997; Zhu et al. 2007), with heterogeneous temporal and spatial patterns (Figs. 5a, c, Table 2).

\subsection{Spatial changes and control mechanisms of PUE in the north-south transect forests over China}

Generally, an increasing trend in PUE (2000-2010) was observed in the south of the TNSTF (Fig. 2d), and the PUE was higher in the northeastern part of Inner Mongolia with deciduous coniferous forests (Fig. 2b). Similar results were also found in the TNSTF, with average PUEs of $9.43 \mathrm{mg} \mathrm{CO}$ $\mathrm{g}^{-1} \mathrm{H}_{2} \mathrm{O}$ at Changbaishan, $9.27 \mathrm{mg} \mathrm{CO}_{2} \mathrm{~g}^{-1} \mathrm{H}_{2} \mathrm{O}$ at Qianyanzhou, and $6.90 \mathrm{mg} \mathrm{CO}_{2} \mathrm{~g}^{-1} \mathrm{H}_{2} \mathrm{O}$ at Dinghushan ( $\mathrm{Yu}$ et al. 2008). The PUEs (2000-2010) showed an obvious decreased trend in the north and an increased trend in the centre of the TNSTF (Fig. 2d). Across the TNSTF, significantly negative relationships between PUE and climate (AMP and AMT) (Fig. 6b) and positive relationships between PUE and soil factors (Fig. 6b) were observed. Similar to our results, the spatial distribution of PUE was negative correlated with precipitation and temperature in grasslands ( $\mathrm{Mu}$ et al. 2014; Ye et al. 2002) and forests (Yu et al. 2008). Moreover, in our study, the distribution of PUE was mainly correlated with AMT over the TNSTF $\left(R^{2}=-0.52, P<0.05\right.$, Fig. $\left.6 \mathrm{~b}\right)$; similarly, the contribution of temperature was 8.61 times greater than precipitation to the distribution of PUE in Northeast Inner Mongolia (Mu et al. 2014). Although soil nutrition had positive effects on PUE (Fig. 6b), the PUEs could be more related to climate and soil physical properties (soil density, soil texture) (Mu et al. 2014). Namely, compared with climate, lower 
Fig. 8 The relationships between the variation of net primary productivity (NPP) and the temporal dynamics of climate factors in warm temperate deciduous broad-leaved forests (WTDBF) from 2000 to 2010 , the variations of precipitation use efficiency (PUE), and the temporal dynamics of climate factors in temperate coniferous broad-leaved mixed forests (TCBMF) from 2000 to 2010. Graphs a and b represent the relationships between NPP and annual mean temperature (AMT), NPP, and annual mean precipitation (AMP), respectively; graphs $\mathbf{c}$ and $\mathbf{d}$ represent the relationships between PUE and AMT, PUE, and AMP, respectively
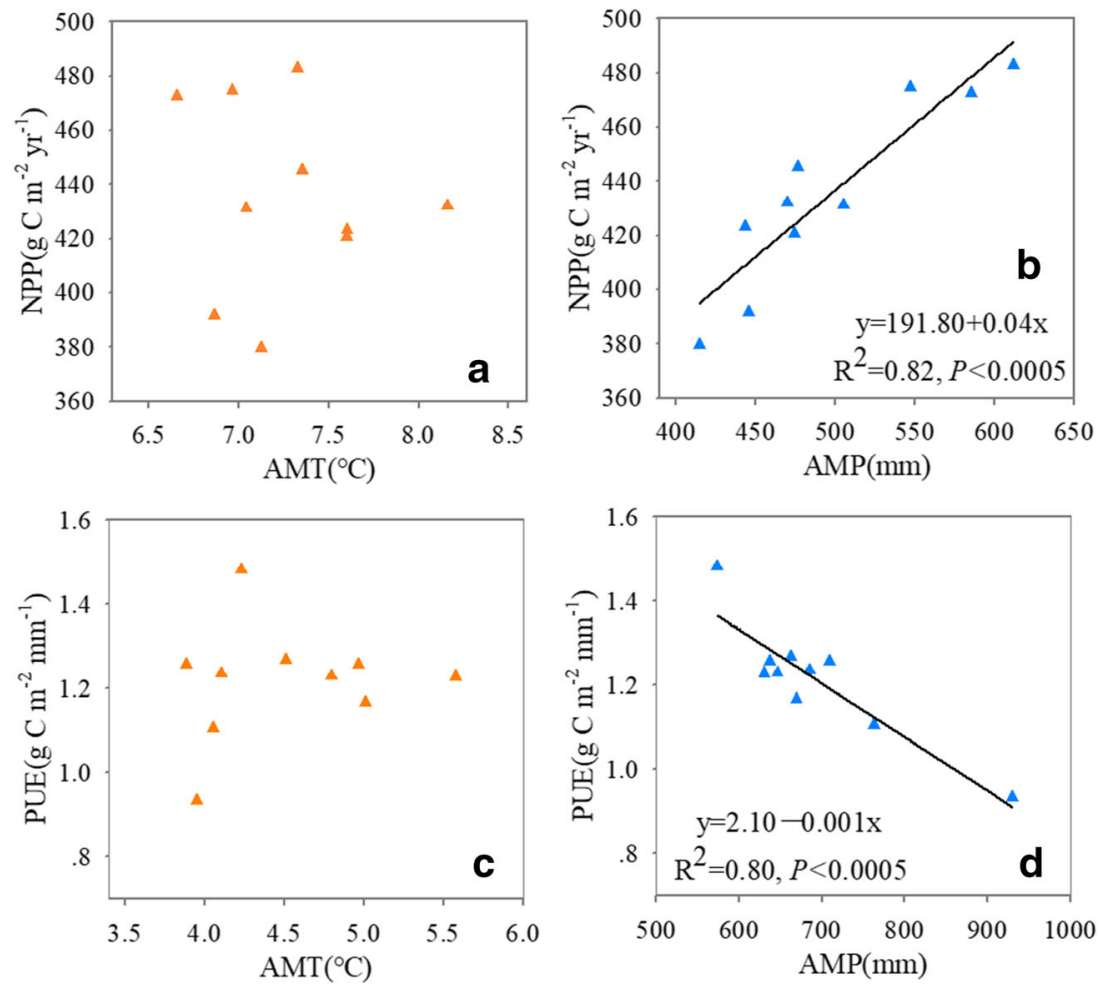

relationships between soil nutrition and PUE were detected in our study (Fig. 6b).

The highest PUE was found in CDCF, with a value of $1.39 \mathrm{~g} \mathrm{C} \mathrm{m}^{-2} \mathrm{~mm}^{-1}$ (Fig. 2b, Table 2). Compared with evergreen plants, higher stomatal conductance in deciduous plants (CDCF) was beneficial to the absorption of $\mathrm{CO}^{2}$ for photosynthesis (Mu et al. 2014), and thus, higher PUE was found in deciduous plants (CDCF). Experimental results also demonstrated that the PUE of deciduous plants was significantly higher than that of evergreen plants in the two tropical rainforest types in Xishuangbanna (Qu et al. 2001). In addition, the AMP for the highest PUE was $442 \mathrm{~mm}$ (data not shown) in CDCF, which was relatively lager than that $(\sim$ $400 \mathrm{~mm}$ ) in grassland with the highest PUE in Inner Mongolia ( $\mathrm{Mu}$ et al. 2014). Meanwhile, a relatively higher PUE was detected in TCBMF (Fig. 2b, Table 2). The AMT $\left(4.51^{\circ} \mathrm{C}\right)$ in TCBMF was much lower than the average growing season temperature $\left(8.20^{\circ} \mathrm{C}\right)$ (Wang et al. 2004) for forests in China, resulting in lower transpiration and high tolerance to water stress for plants. Thus, the plants with high PUEs in TCBMF were highly tolerant to water stress because of the low temperature (Table 2). With the limited absorption of water resources $(497 \mathrm{~mm})$ in TCBMF, the plant photosynthetic and conservative water use strategies in dry regions are primarily to maintain growth and combat water stress (Jobbágy and Sala 1993; Paruelo et al. 1999), leading to a greater PUE in TCBMF. Previous studies pointed out that the distribution of PUE across the TNTSF was mainly controlled by temperature and precipitation (Yu et al. 2008); however, both climate factors and soil factors significantly influenced the distribution of PUE in our study (Fig. 6b).

Notably, our analysis showed that the temporal dynamics in PUE were mainly mediated by AMP at regional scale (Fig. 5c). Moreover, although most regions of PUE were significantly correlated with AMP in space (Fig. 5c), only the PUE in TCBMF showed a significantly decreasing trend from 2000 to 2010 (Table 2). The decrease of PUE in TCBMF was mainly affected by the increase in AMP (Figs. 3c and 8d, Table 2). Because anaerobic environments and nutrition loss (Ye et al. 2002) could be caused by the increase in AMP (more than $690 \mathrm{~mm}$ ) in TCBMF, and these both inhibit forest plants photosynthesis when AMP is less than $850 \mathrm{~mm}$ in China (Yu et al. 2008) as a result of a lower PUE. Additionally, on the Tibetan Plateau, a negative relationship between AMP and PUE was also demonstrated in forests for AMP variations from 470 to $535 \mathrm{~mm}$ and $650-845 \mathrm{~mm}$ (Ye et al. 2002) because PUE was closely associated with water conditions (Ehleringer and Cooper 1988; Fischer and Turner 1978). Similarly, our results indicated that PUE was significantly negatively correlated with AMP when AMP varied between 587 and $876 \mathrm{~mm}$ in TCBMF $\left(R^{2}=0.80, P<0.0005\right.$, Fig. $\left.8 \mathrm{~d}\right)$. However, different temporal dynamic patterns of PUE responses to climate change were demonstrated in different ecosystems or regions. Specifically, a negative relationship, nonrelationship, and positive relationship between temperature and PUE were revealed in grassland ecosystems across Inner Mongolia when AMP ranged from 0-220 mm, 220-310 mm, and $>310 \mathrm{~mm}$, respectively ( $\mathrm{Mu}$ et al. 2014). Other results 
indicated that there were negative, positive, and negative responses of PUE to precipitation in those regions when AMP was less than $100 \mathrm{~mm}$ and ranged from 100 to $600 \mathrm{~mm}$ (Yongfei et al. 2008) and 650-1500 mm (Huxman et al. 2004), respectively.

\section{Conclusions}

Our results indicated that the spatial distribution of NPP in the TNSTF showed an increasing trend from north to south during 2000-2010, whereas increasing and decreasing trends in PUE were observed in the southern and northern parts of the TNSTF, respectively. Across the TNSTF, the link between environmental factors (climate and soil factors) and NPP demonstrated that the spatial distribution of NPP was mainly controlled by climate factors. However, the findings indicated that both climate and soil factors played important roles in shaping the spatial distribution of PUE. Moreover, the increases in temperature and precipitation accounted for the increase in forests' NPPs, especially for the significantly changed NPP in WTDBF. However, the significantly negative relationships between AMP and PUE proved that water conditions were closely associated with forests' PUEs in the TNSTF. Thus, the decrease in PUE was due to the increase in precipitation in TCBF.

Funding information This research was funded by the National Natural Science Foundation of China (grant no. 41871040, 41501057 and 41661144045), and West Light Foundation of the Chinese Academy of Sciences.

Data availability The datasets generated and/or analyzed during the current study are available from the corresponding author on reasonable request.

\section{Compliance with ethical standards}

Conflict of interest The authors declare that they have no conflict of interest.

\section{References}

Acquaye DK (1963) Some significance of soil organic phosphorus mineralization in the phosphorus nutrition of cocoa in Ghana. Plant Soil 19:65-80

Bai Y, Wu J, Xing Q, Pan Q, Huang J, Yang D, Han X (2008) Primary production and rain use efficiency across a precipitation gradient on the Mongolia plateau. Ecology 89:2140-2153

Brümmer C, Black TA, Jassal RS, Grant NJ, Spittlehouse DL, Chen B, Nesic Z, Amiro BD, Arain MA, Barr AG (2012) How climate and vegetation type influence evapotranspiration and water use efficiency in Canadian forest, peatland and grassland ecosystems. Agric For Meteorol 153:14-30

Cao MK, Tao B, Ke-Rang LI, Shao XM, Stephen D (2003) Interannual variation in terrestrial ecosystem carbon fluxes in China from 1981 to 1998. Acta Bot Sin 45:552-560

Chiu CY, Chen TH, Imberger K, Tian G (2006) Particle size fractionation of fungal and bacterial biomass in subalpine grassland and forest soils. Geoderma 130:265-271

Cleveland CC, Townsend AR, Taylor P, Alvarez-Clare S, Bustamante MMC, Chuyong G, Dobrowski SZ, Grierson P, Harms KE, Houlton BZ (2011) Relationships among net primary productivity, nutrients and climate in tropical rain forest: a pan-tropical analysis. Ecol Lett 14:939-947

Cramer W, Bondeau A, Woodward FI, Prentice IC, Betts RA, Brovkin V, Cox PM, Fisher VA, Foley JA, Friend ADJ (2001) Global response of terrestrial ecosystem structure and function to $\mathrm{CO} 2$ and climate change: results from six dynamic global vegetation models. Glob Chang Biol 7:357-373

Ehleringer JR, Cooper TA (1988) Correlations between carbon isotope ratio and microhabitat in desert plants. Oecologia 76:562-566

Fang S (1992) The eco-geographical distribution of forest insects in China. J Forestry Res 3(2):13-22

Fang J, Piao S, Field CB, Pan Y, Guo Q, Zhou L, Peng C, Tao S (2003) Increasing net primary production in China from 1982 to 1999. Front Ecol Environ 1:293-297

Fang O, Wang Y, Shao X (2014) Advances in study of reconstruction of regional forest net primary productivity based on tree rings. Prog Geogr 33:1039-1046

Fischer RA, Turner NC (1978) Plant productivity in the arid and semiarid zones. Annu Rev Plant Biol 29:277-317

Gao Q, Zhang X (1997) A simulation study of responses of the Northeast China transect to elevated $\mathrm{CO} 2$ and climate change. Ecol Appl 7: 470-483

Guo F, Yost RS (1998) Partitioning soil phosphorus into three discrete pools of differing availability1. Soil Sci 163:822-833

Houghton RA (2007) Balancing the global carbon budget. Annu Rev Earth Planet Sci 35:313-347

Huang F, Xu S (2016) Spatio-temporal variations of rain-use efficiency in the west of Songliao plain, China. Sustainability 8:308

Huang M, Piao S, Janssens IA, Zhu Z, Wang T, Wu D, Ciais P, Myneni RB, Peaucelle M, Peng S (2017) Velocity of change in vegetation productivity over northern high latitudes. Nat Ecol Evol 1(11): 1649-1654

Huxman TE, Smith MD, Fay PA, Knapp AK, Rebecca Shaw M, Loik ME, Smith SD, Tissue DT, Zak JC, Weltzin JF (2004) Convergence across biomes to a common rain-use efficiency. Nature 429:651654

Jennings KA, Guerrieri R, Vadeboncoeur MA, Asbjornsen H (2016) Response of Quercus velutina growth and water use efficiency to climate variability and nitrogen fertilization in a temperate deciduous forest in the northeastern USA. Tree Physiol 36:428-443

Jobbágy EG, Sala OE (1993) Controls of grass and shrub aboveground production in the Patagonian steppe. Kluwer Academic Publishers $541-549 \mathrm{pp}$

Kato T, Kimura R, Kamichika M (2004) Estimation of evapotranspiration, transpiration ratio and water-use efficiency from a sparse canopy using a compartment model. Agric Water Manag 65:173-191

Kerr J, Packer L (1998) The impact of climate change on mammal diversity in Canada. Environ Monit Assess 49:263-270

Kwak JH, Lim SS, Lee KS, Viet HD, Matsushima M, Lee KH, Jung K, Kim HY, Lee SM, Chang SX (2016) Temperature and air pollution affected tree ring $\delta 13 \mathrm{C}$ and water-use efficiency of pine and oak 
trees under rising $\mathrm{CO} 2$ in a humid temperate forest. Chem Geol 420: $127-138$

Le HH, Bingham RL, Skerbek W (1988) Relationship between the variability of primary production and the variability of annual precipitation in world arid lands. J Arid Environ 15:1-18

Lehouerou HN (1984) Rain-use efficiency: a unifying concept in aridland ecology. J Arid Environ 7:213-247

Li Y, Liao S, Chi G, Liao Q (2004) NPP distribution related to the terrains along the north-south transect of eastern China. Sci Bull 49:617-624

Li H, Liu G, Fu B (2013) Spatial variations of rain-use efficiency along a climate gradient on the Tibetan plateau: a satellite-based analysis. Int J Remote Sens 34:7487-7503

Li H, Wei X, Zhou H (2015) Rain-use efficiency and NDVI-based assessment of karst ecosystem degradation or recovery: a case study in Guangxi, China. Environ Earth Sci 74:1-8

Lieth H, Whittaker RH (1975) Primary productivity of the biosphere. Springer-Verlag

Limousin JM, Yepez EA, Mcdowell NG, Pockman WT (2015) Convergence in resource use efficiency across trees with differing hydraulic strategies in response to ecosystem precipitation manipulation. Funct Ecol 29:1125-1136

Ling LU, Xin LI, Huang CL, Veroustraete F (2007) Analysis of the Spatio-temporal characteristics of water use efficiency of vegetation in West China. J Glaciol Geocryol 29:777-784

Mao D, Wang Z, Wu C, Song K, Ren C (2014) Examining forest net primary productivity dynamics and driving forces in northeastern China during 1982-2010. Chin Geogr Sci 24:631-646

Maseyk K, Hemming D, Angert A, Leavitt SW, Dan Y (2011) Increase in water-use efficiency and underlying processes in pine forests across a precipitation gradient in the dry Mediterranean region over the past 30 years. Oecologia 167:573-585

Monteith JL (1972) Solar radiation and productivity in tropical ecosystems. J Appl Ecol 9:747-766

Morales P, Sykes MT, Prentice IC, Smith P, Smith B, Bugmann H, Zierl B, Friedlingstein P, Viovy N, Sabate S (2010) Comparing and evaluating process-based ecosystem model predictions of carbon and water fluxes in major European forest biomes. Glob Chang Biol 11:2211-2233

Morin X, Fahse L, Jactel H, Schererlorenzen M, Garcíavaldés R, Bugmann H (2018) Long-term response of forest productivity to climate change is mostly driven by change in tree species composition. Sci Rep 8:5627

Mu SJ, Zhou KX, Qi Y, Chen YZ, Fang Y, Zhu C (2014) Spatio-temporal patterns of precipitation-use efficiency of vegetation and their controlling factors in Inner Mongolia. Chin J Plant Ecol 38(1):1-16

Nock CA, Baker PJ, Wanek W, Leis A, Grabner M, Bunyavejchewin S, Hietz P (2011) Long-term increases in intrinsic water-use efficiency do not lead to increased stem growth in a tropical monsoon forest in western Thailand. Glob Chang Biol 17:1049-1063

Ouyang S, Wang X, Wu Y, Sun OJ (2014) Contrasting responses of net primary productivity to inter-annual variability and changes of climate among three forest types in northern China. J Plant Ecol 7:309320

Pan Y, Birdsey R, Hom J, Mccullough K (2009) Separating effects of changes in atmospheric composition, climate and land-use on carbon sequestration of U.S. mid-Atlantic temperate forests. For Ecol Manag 259:151-164

Papanikolaou N, Britton AJ, Helliwell RC, Johnson D (2010) Nitrogen deposition, vegetation burning and climate warming act independently on microbial community structure and enzyme activity associated with decomposing litter in low-alpine heath. Glob Chang Biol $16: 3120-3132$
Paruelo JM, Lauenroth WK, Burke IC, Sala OE (1999) Grassland precipitation-use efficiency varies across a resource gradient. Ecosystems 2:64-68

Piao S, Ciais P, Lomas M, Beer C, Liu H, Fang J, Friedlingstein P, Huang Y, Muraoka H, Son Y (2011) Contribution of climate change and rising $\mathrm{CO} 2$ to terrestrial carbon balance in East Asia: a multi-model analysis. Glob Planet Chang 75:133-142

Qu CM, Han X-G, Su B, Huang J, Jiang G (2001) The characteristics of foliar $\delta 13 \mathrm{C}$ values of plants wateruse efficiency indicated by $\delta 13 \mathrm{C}$ values in two fragmentedrainforests in Xishuangbanna, Yunnan. Acta Bot Sin 43:186-192

Ren W, Tian H, Tao B, Chappelka A, Sun G, Lu C, Liu M, Chen G, Xu X (2011) Impacts of tropospheric ozone and climate change on net primary productivity and net carbon exchange of China's forest ecosystems. Glob Ecol Biogeogr 20:391-406

Ross DJ, Tate KR, Feltham CW (1996) Microbial biomass, and C and N mineralization, in litter and of adjacent montane ecosystems in a southern beech (Nothofagus) forest and a tussock grassland. Soil Biol Biochem 28:1613-1620

Sala OE, Parton WJ, Joyce LA, Lauenroth WK (1988) Primary production of the central grassland region of the United States. Ecology 69: $40-45$

Sitch S, Huntingford C, Gedney N, Levy PE, Lomas M, Piao SL, Betts R, Ciais P, Cox P, Friedlingstein P (2008) Evaluation of the terrestrial carbon cycle, future plant geography and climate-carbon cycle feedbacks using five dynamic global vegetation models (DGVMs). Glob Chang Biol 14:2015-2039

Steffen W, Noble I, Canadell J, Apps M, Schulze ED, Jarvis PG (1998) The terrestrial carbon cycle: implications for the Kyoto protocol. Science 280:1393

Sun J, Du W (2017) Effects of precipitation and temperature on net primary productivity and precipitation use efficiency across China's grasslands. Gisci Remote Sens 5:1-17

Sun J, Cheng GW, Li WP (2013) Meta-analysis of relationships between environmental factors and aboveground biomass in the alpine grassland on the Tibetan Plateau. Biogeosciences 10:1707-1715

Wang L (2010) The vegetation NPP dynamic along the north south transect of East China (NSTEC) based on IBIS simulation. Institute, China Forest Science Research (in Chinese)

Wang XP, Zhang L, Fang JY (2004) Geographical differences in alpine timberline and its climatic interpretation in China. Acta Geograph Sin 59:871-879

Wang P, Sun R, Hu J, Zhu Q, Zhou Y, Li L, Chen JM (2007) Measurements and simulation of forest leaf area index and net primary productivity in northern China. J Environ Manag 85:607-615

Wang S, Zhou L, Chen J, Ju W, Feng X, Wu W (2011) Relationships between net primary productivity and stand age for several forest types and their influence on China's carbon balance. J Environ Manag 92:1651-1662

Williams JE (2000) The biodiversity crisis and adaptation to climate change: a case study from Australia's forests. Environ Monit Assess 61:65-74

Xian JR, Chen GP, Liu YZ, Xu XX, Yang ZB, Yang WQ (2017) Positive adaptation of Salix eriostachya to warming in the treeline ecotone, east Tibetan Plateau. J Mt Sci 14:346-355

Xie J, Chen J, Sun G, Zha T, Yang B, Chu H, Liu J, Wan S, Zhou C, Ma H (2016) Ten-year variability in ecosystem water use efficiency in an oak-dominated temperate forest under a warming climate. Agric For Meteorol 218-219:209-217

Yang Y, Fang J, Fay PA, Bell JE, Ji C (2010) Rain use efficiency across a precipitation gradient on the Tibetan Plateau. Geophys Res Lett 37: L15702. https://doi.org/10.1029/2010GL043920 
Ye H, Wang JB, Huang M, Qi SH (2002) Spatial pattern of vegetation precipitation use efficiency and its response to precipitation and temperature on the Qinghai-Xizang Plateau of China. Chinese J Plant Ecol 36(12):1237-1247

Yin H, Zhengguo LI, Wang Y, Cai F (2011) Assessment of desertification using time series analysis of hyper-temporal vegetation Indicator in Inner Mongolia. Acta Geograph Sin 66:653-661

Yongfei B, Jianguo W, Qi X, Qingmin P, Jianhui H, Dianling Y, Xingguo $\mathrm{H}$ (2008) Primary production and rain use efficiency across a precipitation gradient on the Mongolia plateau. Ecology 89:2140-2153
Yu G, Song X, Wang Q, Liu Y, Guan D, Yan J, Sun X, Zhang L, Wen X (2008) Water-use efficiency of forest ecosystems in eastern China and its relations to climatic variables. New Phytol 177:927-937

Zhu WQ, Pan YZ, Zhang JS (2007) Estimation of net primary productivity of Chinese terrestrial vegetation based on remote sensing. J Plant Ecol 31:413-424

Publisher's note Springer Nature remains neutral with regard to jurisdictional claims in published maps and institutional affiliations. 